\title{
THE RECOVERY OF BACTERIA FROM THE TOXIC EFFECTS OF PENICILLIN ${ }^{1}$
}

\author{
BY HARRY EAGLE
}

(From the Section on Experimental Therapeutics, National Institutes of Health, U. S. Public Health Service, Bethesda 14, Maryland)

There is considerable evidence that the therapeutic action of penicillin is determined primarily by the total length of time for which it remains at concentrations effective against the particular organism. It is, however, equally clear that the exposure to penicillin need not be continuous. Injections of aqueous penicillin may be given so infrequently that for an appreciable period of time the serum concentrations of the drug are below the limits effective against the particular organism, and yet such widely-spaced injections may be fully effective therapeutically. This raises the question as to why the bacteria fail to remultiply during the time that the serum concentrations are less than that necessary to kill the organisms in vitro. Several of the possible explanations are apparently not valid. We have not found the bacteria we have studied to be appreciably more sensitive to penicillin in vivo than they are in vitro. The concentrations necessary to effect cure are of the same order of magnitude as those required to kill the bacteria in the test tube. Similarly, we have not found that penicillin, after its intramuscular injection in aqueous solution, persists at effective levels in the tissues for a significantly longer period than in the blood.

This paper will describe some experimental data which may throw some light on this problem. The clue was the observation by Parker and Marsh (1) that after staphylococci had been exposed to penicillin, they did not immediately remultiply on the removal of the drug. Instead, there followed a period of recovery during which they remained essentially constant in number, and during which they were presumably recovering from the toxic effects of the drug. We have found this phenomenon to be observed with every bacterial species so far studied, whether with group A, group B or

\footnotetext{
1 Presented at the Second National Symposium on Recent Advances in Antibiotics Research held in Washington, D. C., April 11-12, 1949, under the auspices of the Antibiotics Study Section, National Institutes of Health, Public Health Service, Federal Security Agency.
}

group $\mathrm{C} \beta$-hemolytic streptococci, $\alpha$-hemolytic streptococci, type I or type III pneumococci, Staphylococcus aureus, Staphylococcus albus, or Streptococcus fecalis. After the bacteria have been exposed to penicillin, on the removal of the drug there follows a variable recovery period during which their numbers remain constant for a period of two, four, six, or even eight to 10 hours. Only after this period of recovery do the organisms begin to multiply at their normal rate (Figure 1). In some instances the toxic effect on the bacteria was manifested by a reduced rate of multiplication on the removal of penicillin, rather than an absolute bacteriostasis (Figure 2).

The rate at which this toxic effect is initiated, and the duration of the following recovery period, vary with individual bacterial species, and are affected also by two additional factors. One is the concentration of the drug to which the bacteria had been exposed (Figure 3). The toxic effect is initiated only by concentrations eventually bactericidal to the organism. The rate at which the toxic effect develops varies with the concentration of penicillin, and reaches a maximum at the concentration most rapidly bactericidal for the particular organism. Beyond that maximum, even a 10,000-fold increase in the concentration of penicillin does not further accelerate the rate at which the toxic effect is initiated.

The duration of the recovery period is affected also by the time for which the bacteria had been exposed to penicillin. With some strains (Figure 4) the toxic effect reaches its maximum within one to two hours, and even 24-hour exposure to penicillin does not significantly prolong the duration of the following recovery period. With other strains, however, the duration of the recovery period increases directly and continuously with the duration of the preceding exposure to penicillin (Figure 5).

It is apparent that a recovery period during which the organisms remain static in number provides a valuable margin of safety in the thera- 


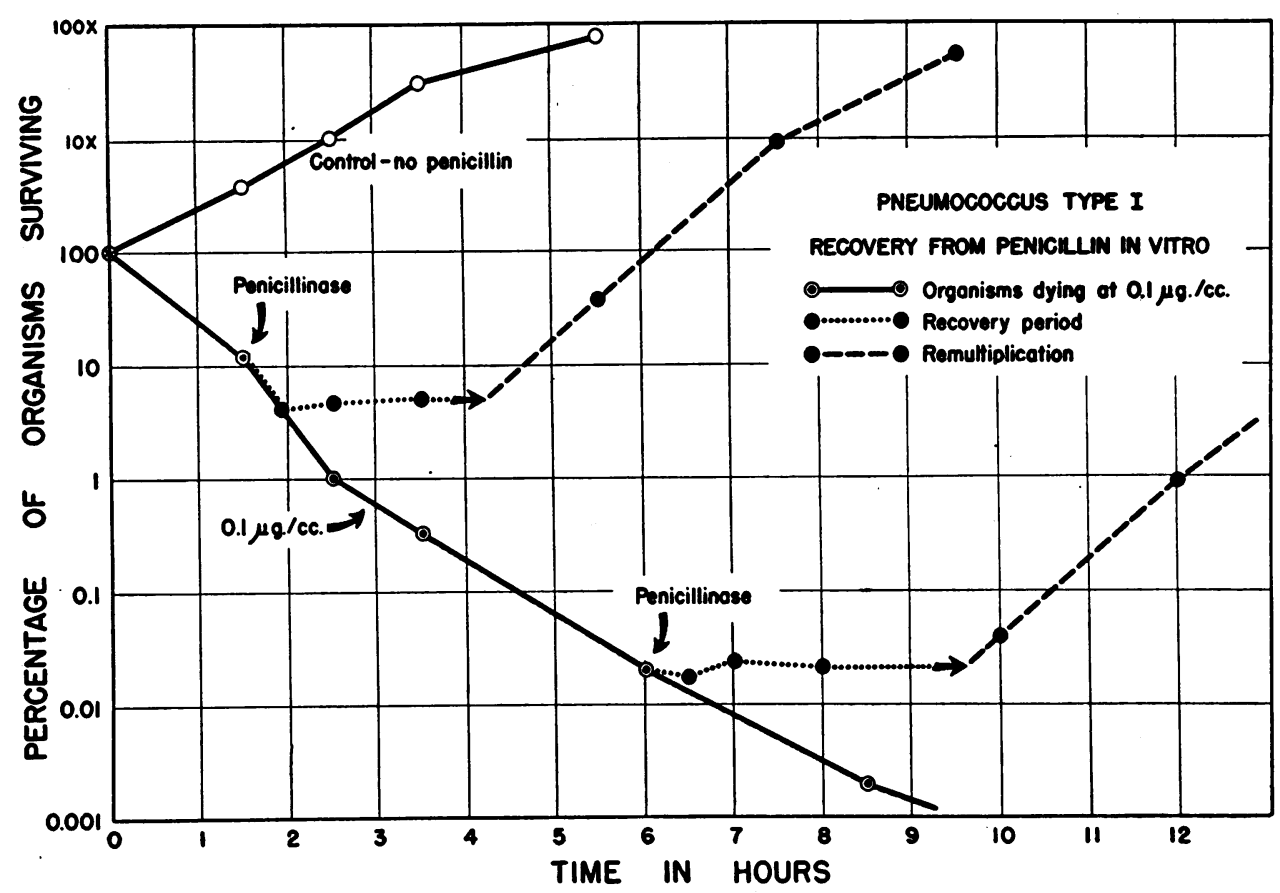

FIG. 1

peutic use of the drug, a period during which the organisms will not multiply even in the absence of penicillin. The therapeutic importance of this phenomenon, however, goes beyond the mere failure of the bacteria to multiply. We have found that during this recovery period, bacteria previously exposed to penicillin are extraordinarily susceptible to the defense mechanisms of the body. Even highly virulent organisms against which the body ordinarily has so little defense that one or

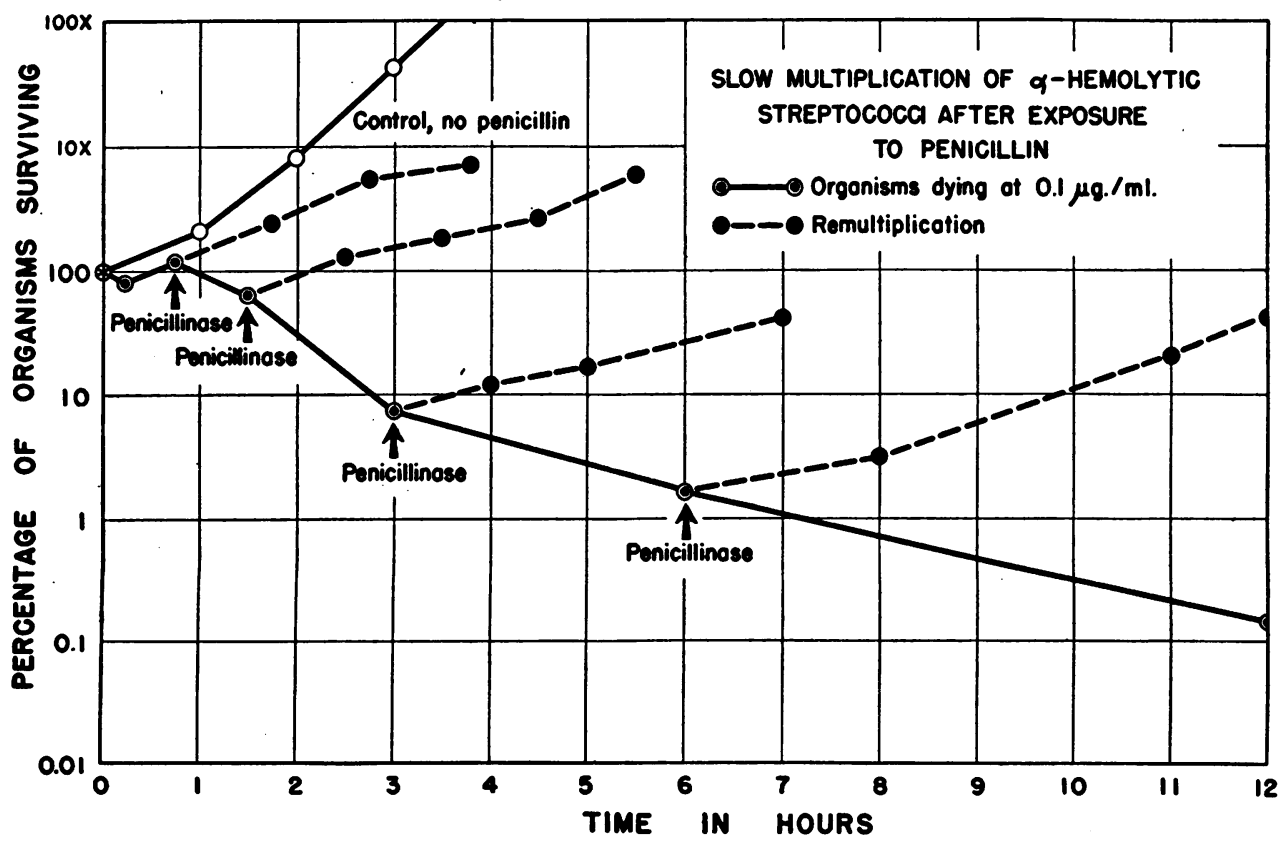

Fig. 2 


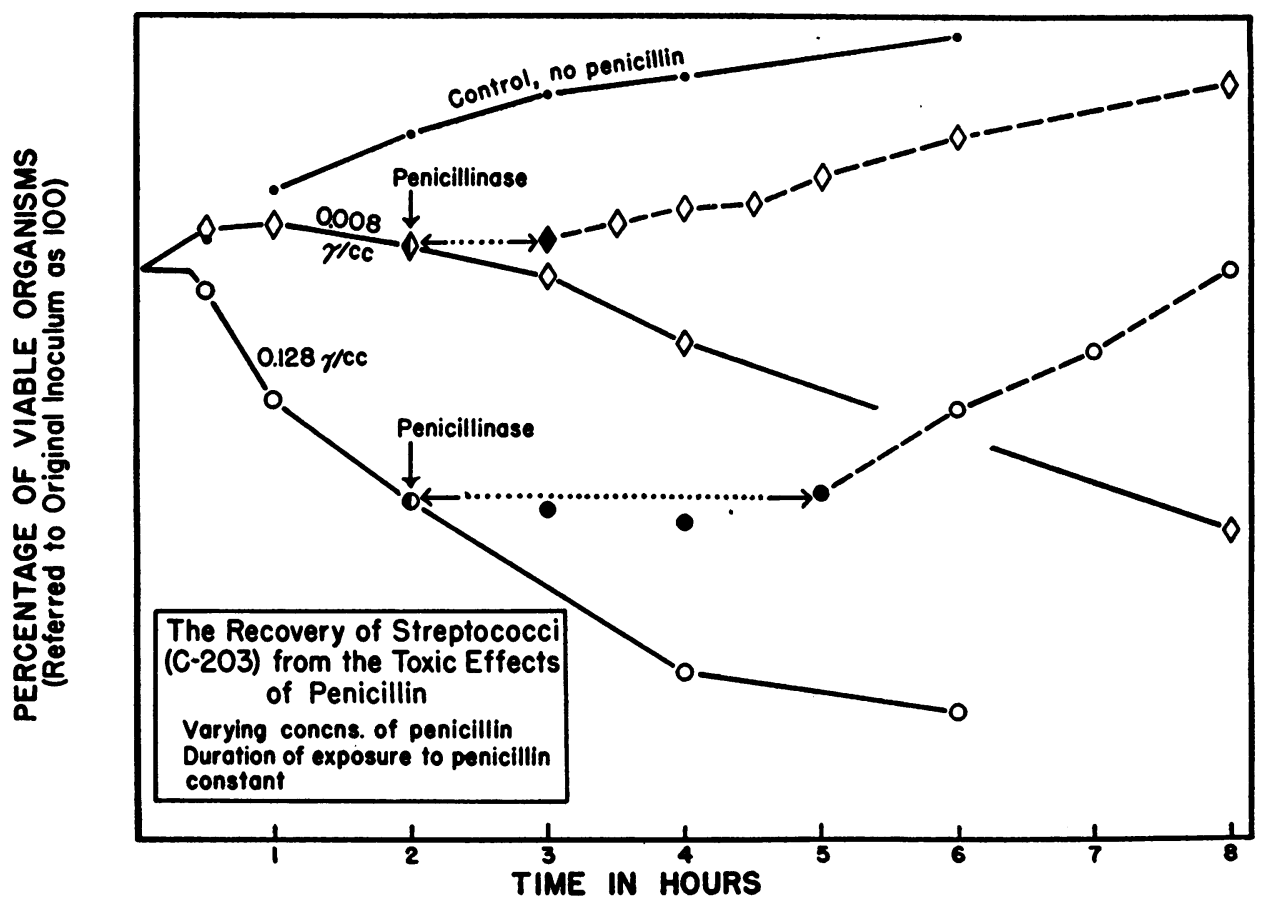

Fig. 3

two bacteria suffice to initiate a fatal infection become relatively avirulent after exposure to penicillin. In order to initiate a fatal infection, one must inject, not one, but $100,1,000$, or in several ex- periments even 5,000 of these recovering but viable bacteria. As the bacteria recover from the toxic effects of penicillin, their virulence slowly returns, reaching its normal level at the time

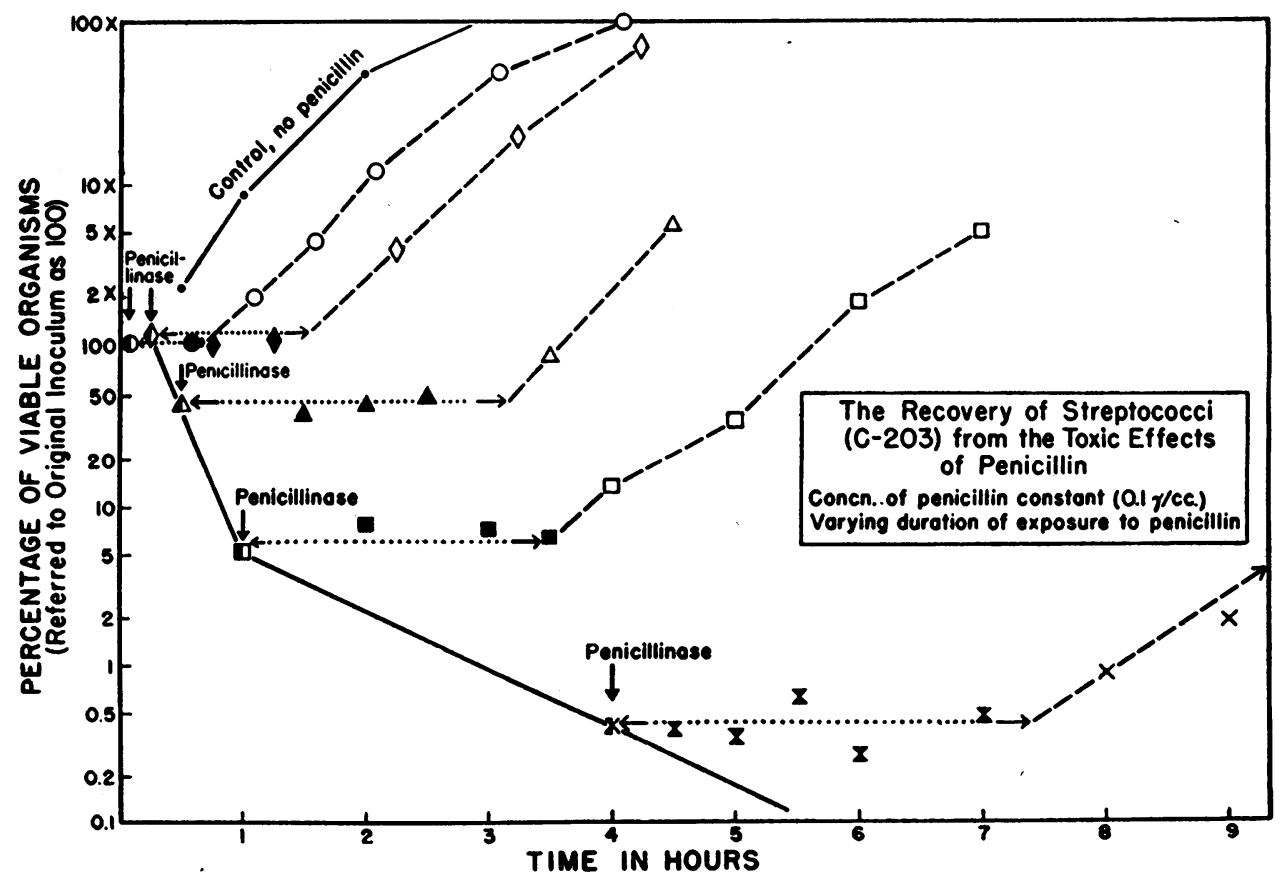

Fic. 4 


\section{RECOVERY FROM PENICILLIN}

(GROUP B) $\beta$-HEMOLYTIC STREPTOCOCCI $(256 \mu \mathrm{g} / \mathrm{ml})$

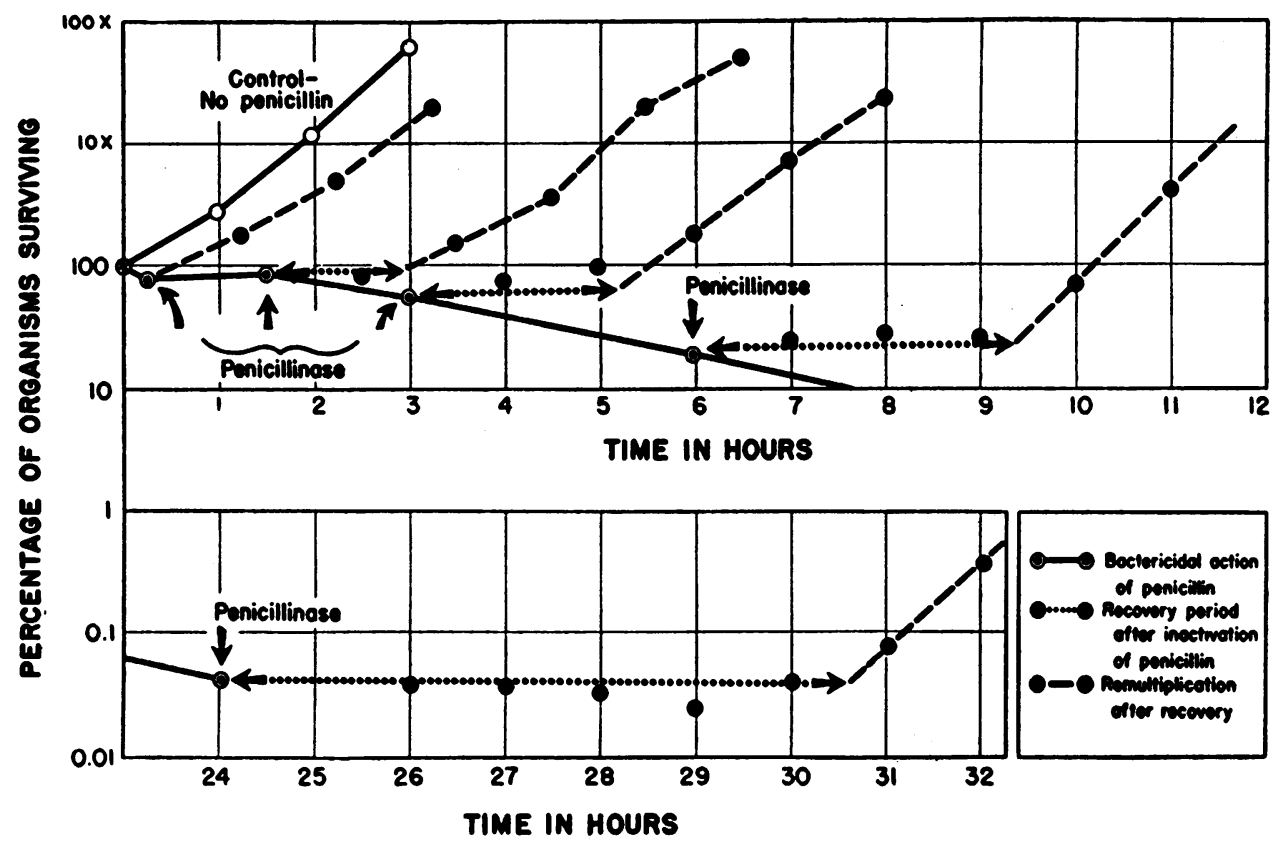

FIG. 5

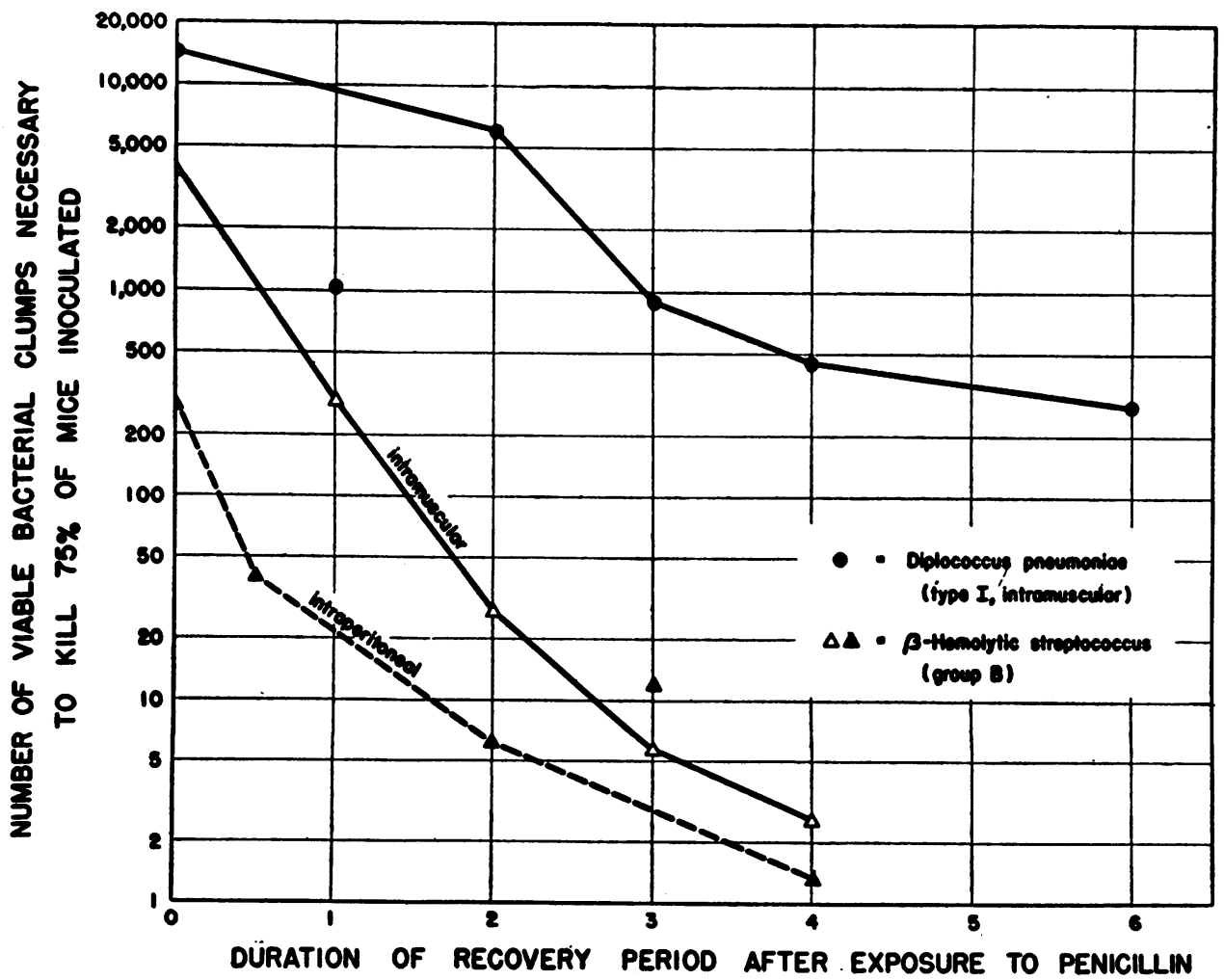

Fig. 6 
that the bacteria resume multiplication in the test tube (Figure 6). This decreased virulence of bacteria which have been acted on by penicillin can only mean that the organisms have become susceptible to the defense mechanisms of the host. One must inoculate as many as 100 or 1,000 bacteria in order to have at least one organism surviving by the time the bacteria have recovered sufficiently to resume multiplication and regain their normal virulence.

The therapeutic implications are two-fold. In the first place, bacteria should be, and are, killed by penicillin even more rapidly in vivo than they are in vitro. The bactericidal action in the infected animal is the sum of the direct effect of penicillin itself, plus the bactericidal action of the host mechanisms on organisms which are being acted on by the drug and thereby rendered susceptible. This has been found to be the case in a number of acute experimental infections of rabbits and mice. The relative quantitative importance of these two mechanisms is under present study. In the second place, the therapeutic action of penicillin persists well beyond the time for which the drug remains at effective levels. For a varying period of time after penicillin has fallen below bactericidal concentrations, the damaged but viable bacteria continue to die under the impact of the host defense mechanisms. There is reason to believe that the number of bacteria killed during this penicillin-free period is usually less than those killed by the drug and the host during the period of penicillin action. The recovery period is nevertheless of major importance in that it provides a necessary and desirable margin of safety in the therapeutic use of penicillin. Even though the total length of time for which penicillin remains at effective levels may be the factor primarily determining its therapeutic efficacy, those levels need not be continuously maintained.

Studies are in progress to determine whether humoral or cellular host mechanisms are concerned in the death of bacteria which have been damaged by penicillin.

\section{BIBLIOGRAPHY}

1. Parker, R. F., and Marsh, H. C., The action of penicillin on staphylococcus. J. Bact., 1946, 51, 181. 